\title{
The Good-Faith Purchaser: Markets, Culture, and the Legal System.*
}

\author{
Giuseppe Dari-Mattiacci, Carmine Guerriero, Zhenxing Huang
}

December 26, 2011

\begin{abstract}
A key institutional setting is the set of rules balancing the use of coercion to the one of markets for transferring property rights. Even if all legal systems forbid theft ex ante, different societies provide different ex post solutions to the conflict arising between the original owner and the good-faith buyer of a good with defective title. These rules range from the full protection of the original owner's property right to the full protection of the buyer's reliance on contract. Looking at a world in which only intermediaries can transfer goods from original owners to buyers by using either coercion or markets, we prove that: 1. Society should accept coercion, if buyers value the good more than original owners, and minimize it, otherwise; 2 . In the first of the two cases, provided that the preference polarization is not too wide, there are separating equilibria in which moral intermediaries - i.e., those for whom coercion entails a sufficiently high moral cost - signal their proper title by charging higher prices; 3 . In the second of the two cases, the market shrinks because moral intermediaries refrain from coercion. Thus, mature economies - i.e., those in which original owners tend to value goods more than buyers - will move toward buyer protection, the higher is the share of moral intermediaries (lower is the quality of the legal system) because of the lower extent of coercion (lower impact of public enforcement). Estimates, based on a panel of 148 countries over the 1981-2011 period, are consistent with this prediction. Keywords: Property Rights; Market; Culture; Public Enforcement; Good Faith. JEL classification: P14; L11; Z10; K11.
\end{abstract}

\footnotetext{
${ }^{*}$ We would like to thank Arthur Salomons, who has coauthored a companion project on the law and economics of good-faith purchase (Dari-Mattiacci et al., 2011), Anghel Negriu and Sander Verrips for the outstanding research assistance, all the national contributors whose names are listed in the internet appendix, and Jan Tuinstra. The financial support provided by the Netherlands Organisation for Scientific Research (VIDI grant 016.075.332) is gratefully acknowledged. Giuseppe Dari-Mattiacci and Carmine Guerriero: ACLE, University of Amsterdam. Zhenxing Huang: Erasmus University Rotterdam.
} 


\section{Introduction}

A key institutional setting is the set of rules balancing the use of coercion to the one of markets for transferring property rights. All legal systems prevent coercion ex ante by criminalizing not only theft but also fraud, and by undoing the effects of contracts where a party has coerced the other-e.g., unjust enrichment laws. Yet, different societies provide different ex post solutions to the conflict arising between the original owner and the goodfaith buyer of a good with defective title. These rules range from the full protection of the original owner's property right to the full protection of the buyer's reliance on contract. This paper lays out a theoretical model for thinking about this issue and explores its empirical implications using a panel of 148 countries over the 1981-2011 period.

In the model, homogeneous goods in the hand of a group of original owners can be transferred to a group of potential buyers only by intermediaries, who can either buy or steal from the original owners. Intermediaries are either "moral" and suffer a psychological cost from stealing or "immoral" and thus numb to feelings of guilt. The intermediary type is the only piece of private information. Each intermediary decides first whether to steal, buy, or exit the market and, then, if still in the market, a selling price. Next, the buyer chooses whether to buy. Finally, with an exogenous probability, the legal system observes the title of the good and enforces the law. We consider three rules: 1. owner protection prescribes that a stolen good should be returned to the original owner; 2. good-faith buyer protection allows only good-faith buyers - i.e., those who received an uninformative signal - to retain a stolen goods; 3. full buyer protection permits even bad-faith buyers to retain a stolen good.

Our key results are as follows: 1. Society should accept coercion, if buyers value the good more than original owners, and minimize it, otherwise; 2. In the first of the two cases, provided that the preference polarization is not too wide, there are separating equilibria in which moral intermediaries signal their proper title by charging higher prices; 3 . In the second of the two cases, the market shrinks because moral intermediaries refrain from coercion. Thus, mature economies - i.e., those in which original owners tend to value goods

more than buyers - will move toward buyer protection, the higher is the share of moral intermediaries (lower is the quality of the legal system) because of the lower extent of coercion 
(lower impact of public enforcement). The model's message survives under several alternative assumptions - i.e., 1. original owners can costly protect their property; 2 . the signal is costly for the buyers; 3 . some of the buyers suffer a moral loss from buying a good they know was stolen - and is consistent with estimates based on a panel of 148 countries for which we have information on the relative protection of the buyer vis-a-vis the seller, the strength of a norm of respect for others, and the quality of the public enforcement of the law.

Even if a few studies (Ben-Shahar, 1995; Medina, 2003; Schwartz and Scott, 2011) have built on the least cost avoidance principle to compare different rules on the basis of owner's prevention and buyer's information costs, no previous paper has explained the observed variation in the rules concerning good-faith purchase through the fundamental characteristics of society. From this perspective, the present paper offers three contributions. First, for the first time, we provide a theory of "endogenous legal institutions" characterizing how societies, heterogeneous in their endowment of long run moral and enforcement capacity, balance property rights protection and reliance on contract. ${ }^{1}$ Crucially, we do this by endogenizing not only the supply of coercion but also the market structure-i.e., prices and identities of market participants. Second, we test this theory on a comprehensive sets of legal rules regulating the transfers of several key tradable goods. Third, we devise a dataset which could be fruitful used to the inquiry into the details of property rights and contractual institutions formation. As a result, the present paper is complementary to two main bodies of research. While the first looks at the relative importance of contracting versus property rights institutions at the macro level (Acemoglu and Johnson, 2005), the second one sees the legal system as a response to the risk that the majority of market participants is coerced by a subgroup of more powerful special interests (Djankov et al., 2003b; Glaeser and Shleifer, 2003; Guerriero, 2011) or of similarly powerful untrustworthy agents (Aghion et al., 2010).

The rest of the paper is organized as follows. Section 2 describes several cases of good faith acquisition to inform the set up of the model, which focuses on stolen goods and is illustrated in section 3 and 4 . Section 5 test the predictions coming from the model. Section 6 concludes. The appendix gathers proofs, tables, and the description of the data.

\footnotetext{
${ }^{1}$ Other works looking at coercion as an alternative to markets are Piccione and Rubinstein (2007) and Acemoglu and Wolitzky (2011). The latter, however, don't consider the role of society's moral structure.
} 


\section{Property Rights v. Contract Certainty}

The acquisition of a property right can be either original or derivative, i.e. from a previous owner. The occupation of new territories, the capture of wild animals, and the invention of a new product provide paradigmatic examples of original acquisition. In all these cases, the property right accrues directly to the individual. In case of sale, inheritance, gift and other forms of transfer, the individual acquires the property right not directly, but rather through the previous owner. Therefore, if intermediary $I$ steals a good from the original owner $O$ and resells it to a good-faith buyer $B$, who believes that $I$ is the legitimate owner, a conflict arises between $O$ and $B$. Returning the good to $O$ entails strong protection of property, while recognizing $B$ 's right to keep and dispose of the good safeguards reliance on contract.

The sale of stolen goods is only one example of a much broader set of analogous problems, as illustrated by the following examples: $I$ buys a good from $O$ and resells it to $B$, but later on the contract between $I$ and $O$ is voided; $O$ stores her good in $I$ 's safe, but $I$ sells it to $B ; I$ sells the same good first to $O$ and later to $B ; I$ works in $B$ 's shop and sells a good to $B$ which she is not authorized to sell. These problems are important only to the extent that some transactions cannot be undone. The ideal solution would be to protect both $O$ 's property right - by having $B$ return the good - and $B$ 's reliance on contract - by having $I$ returning the price paid by $B$. Legal systems offer a set of rules of unjust enrichment whose goal is to undo the effects of voidable of illegal transfers; yet, in reality, the intermediary may often be insolvent or impossible to find and bring to court including because of statutes of limitations. Hence, there are relevant externalities that either the buyer or the original owner will have to bear and society will choose among the many possible gradations of rules ranging between owner protection and full buyer protection by solving a property right versus contract certainty trade off. ${ }^{2}$ Next section characterizes this institutional design problem.

\section{Theory}

Preliminaries.-We consider the interaction among a mass one of intermediaries, a group

\footnotetext{
${ }^{2}$ While the two-thousand-year-old Roman principle of nemo dat quod non habet-i.e., one cannot give something he does not have - stresses owner protection, the thousand-year-old Germanic Hand wahre Hand - hand true hand - principle favors the buyer. The intermediate features observables in modern legal systems have appeared "chaotic" to most commentators (Levmore, 1987; Schwartz and Scott, 2011).
} 
of original owners of a homogeneous good, and one of potential buyers. The last two groups are bigger than the first one and, for sake of simplicity, we assume that they have the same mass equal to one plus an atomistic agent. Being our focus on the type of exchangei.e., coercion or markets - when an intermediary is needed, we posit that original owners and buyers do not interact directly because, for instance, the buyers are physically distant or unfit to use coercion. The intermediaries can buy or steal at most one good and can meet at most one randomly drawn buyer: this detail spares us a set of essentially arbitrary assumptions about the queuing mechanism that agents with the same valuations should follow.

All intermediaries value the good at 0 , all orginal owners at $U>0$ and all buyers at $V>0$. These lvaluations are common knowledge. For sake of simplicity, we maintain that $V$ can either equal $\underline{V} \equiv U-\Delta$ or $\bar{V} \equiv U+\Delta$, where $\Delta$ measures the polarization between buyers and original owners preferences. We consider the two scenarios as describing respectively mature and primitive economies. In the former, indeed, the existence of credit markets and the preference heterogeneity driven by technological progress make unlikely that goods not negotiated on anonymous markets can be valued more by potential buyers. While the valuations of mature and primitive economies buyers can be easily made asymmetric around the value $U$ at the cost of a more cumbersome algebra, having in the same economy buyers with heterogeneous valuation will make our testable prediction a function of the relative size of the high valuing ones. ${ }^{3}$ Yet, provided that the more or less developed economies studied in our empirical exercise are sufficiently mature - i.e, such that original owners are more likely to value goods more than buyers - this dependence will be irrelevant.

Since original owners compete a' la Bertrand in selling their good, intermediaries can buy the goods at the lowest possible price $U$ and resell it at the highest price buyers are willing to pay. A share $\mu$ of the intermediaries is "moral" and bear a psychological cost $m$ from stealing and a share $1-\mu$ is "immoral" and so numb to feelings of guilt. ${ }^{4}$ Building on the expanding evidence on the relevance of intrinsic motivations for economic exchange (Bénabou and Tirole, 2006; Guiso, Sapienza and Zingales, 2009), we assume that:

\footnotetext{
${ }^{3}$ In this case, the size of the high (low) valuation buyers should equal $\bar{n}>1(\underline{n}>1)$ plus one atomistic agent and the one of the intermediaries (buyers) should be $\bar{n}+\underline{n}(\bar{n}+\underline{n}$ plus two atomistic agents). Also $\bar{n}(\underline{n})$ intermediaries should only deal with high (low) valuation buyers.

${ }^{4}$ Should the difference between a "moral" and an "immoral" intermediary be a psychological reward from not stealing, the algebra will be more complicated but the model will not deliver any new main insight.
} 


$$
\text { A1: } m>U \text {. }
$$

Assumption A1 can be relaxed at the cost of increasing the number of equilibria without affecting the main message of the model. Also, given our hypotheses on the relative sizes of the three groups, assumption A1 implies that the moral cost of stealing is larger than the price of the good and ensures that moral intermediaries never steal. Finally, the fact that, on the other hand, buyers do not suffer any moral loss from buying a defective-title good can be justified by the existence of some form of cognitive dissonance due to the lack of direct experience of coercion (Cooper, 2007). In section 4 we evaluate the impact on the testable prediction coming from the basic model of relaxing hypothesis A1.

Timing.-At time $t_{0}$ society chooses among the institutions described below on the basis of the sum of the expected welfare and a set of mean zero preference shocks also discussed below. Next, at time $t_{1}$, the intermediary makes a take-it-or-leave it offer to the buyer. At time $t_{2}$, the buyer first observes a costless signal that is informative with probability $s \leq 1$ only when the good is stolen, and then decide whether to buy or not the good. ${ }^{5}$ Finally, at time $t_{3}$, with probability $q$, the legal system observes the true title of the goods sold and enforces the law. ${ }^{6}$ The case in which the intermediary is caught is not relevant because, under that scenario, the transfer can be undone: i.e., the original owner can reclaim her good from the buyer and the buyer the price from the intermediary. In other words, the issue arises if the intermediary is not a party in the lawsuit or is insolvent. ${ }^{7}$

We consider three rules: 1. owner protection prescribes that a stolen good should be returned to the original owner; 2. good-faith buyer protection allows only good-faith buyers to retain a stolen good; 3. full buyer protection permits even bad-faith buyers to keep a stolen good. A buyer is considered in bad faith for legal purposes whenever she sees an informative signal. ${ }^{8}$ More formally, while the signal is observable and verifiable in court, the price paid is not verifiable so that the inference from its observation is private to the buyer.

\footnotetext{
${ }^{5}$ The signal assumes value 1 only when the good was stolen and the draw is informative and 0 otherwise. Thus, $\hat{s} \in\{0,1\}$ with $\operatorname{Pr}(\hat{s}=0 \mid$ proper title $)=1$ and $\operatorname{Pr}(\hat{s}=1 \mid$ defective title $)=s$.

${ }^{6}$ The court makes asymmetric errors: it may fail to return a stolen good but never returns goods that were not stolen. The probability $q$ is a summary measure of the probability that the public authorities locate the stolen good and prove before the court the original owner's legitimate title.

${ }^{7}$ What drives the results is the differential cost between moral and immoral intermediaries and not the background probability of apprehension and conviction, which could affect the share of immoral intermediaries. ${ }^{8}$ Should the hypothesis be relaxed, owner and good-faith buyer protection will generate the same equilibria.
} 
This assumption squares with the fact that on a resale market transactions could not be subject to registration and multiple resale prices can be difficult to recover.

The probability that a stolen good purchased by the buyer is returned to the original owner is $q<1$ under owner protection, the joint probability of law enforcement and bad faith $s q<q$ under good-faith buyer protection, and zero under full buyer protection. The following simplifying but innocuous hypothesis - see section 4 -relates $s$ to $q$ :

A2: $s \geq q$.

It is easier for a buyer than for the legal system to verify the title of the good because, for instance, she can ask an expert to accompany her for free. In section 4 we look at two more general set ups: when the original owner can protect her property and when the signal is costly. Finally, we assume that $\theta \equiv \Delta / U \in[0,1]$ is not too wide:

A3: $\theta<\theta^{*} \equiv(1-q) q^{-1} \leq 1$.

At a closer look, $\theta$ should be considered an inverse measure of the potential for stealing relative to either buying when $V=\bar{V}$ or exiting the market when $V=\underline{V}$; indeed: 1 . for $V=\bar{V}$, it is the ratio of the potential profit from trading a good with proper title foregone when the legal system recognizes stealing over the cost of acquiring a proper title; 2 . for $V=\underline{V}$, it is the ratio of the loss from preference polarization avoided by exiting the market over the maximum price of a stolen good. If the potential for stealing is sufficiently big and so assumption A3 holds, immoral intermediaries never buy the good to resell it to a $\bar{V}$ buyer and, thus, a high price has an informational content. ${ }^{9}$ Next, we will first analyze the basic model and then evaluate the consequences of relaxing some key assumptions.

\subsection{An Economy With High Valuation Buyers}

Owner protection.-The buyer of a stolen good faces a potential loss equal to the price paid to the intermediary. This loss can be avoided whenever the buyer can infer from the price whether she is purchasing a stolen good. In such a separating equilibrium, a moral intermediary would pay $U$ to acquire the good from the original owner and charge a high price and a bad intermediary would steal the good and charges a low price. As already anticipated, both prices will equal the maximum buyer's willingness to pay. Hence, a moral

\footnotetext{
${ }^{9}$ Given a level of $U$, assumption A3 is more easily satisfied if preferences are less polarized because of, for instance, globalization; also, the hypothesis is without loss of generality when $q<1 / 2$.
} 
intermediary will sell a legitimate good at price $\bar{p}^{h} \equiv \bar{V}$ and the immoral one a good that the buyer will have to return with probability $q$ at a price $\bar{p}^{l} \equiv(1-q) \bar{V}$. This equilibrium is sustained by the fact that a stolen goods offered at a price $\bar{p}^{h} \equiv \bar{V}$ would remain unsold in a fraction $s$ of the cases - i.e., whenever the buyer discovers that the good is stolen. In other words, selling a stolen good for a high price would yield a payoff of $(1-s) \bar{V}<(1-q) \bar{V}$ to the intermediary. This argument also excludes the possibility of a pooling equilibrium, where both intermediaries would charge the same price $\bar{p}^{h}$. All in all, under owner protection there is a unique separating equilibrium and the change of social welfare, defined as the change of the sum of the three agents' payoffs with respect the baseline situation in which original owners enjoy their goods and both the intermediary and the buyer remain dormant, equals $\bar{W}_{O}=\mu(\bar{V}-U)+(1-\mu)(1-q)(\bar{V}-U)$. Hence, the change in social welfare increases with the share of moral intermediaries but declines with the quality of the legal system. This is a straightforward consequence of the fact that buyers value the good more than original owners and, hence, social welfare is negatively affected if the good is returned to the original owner, which in turn happens if the good is stolen and the law is enforced.

Good-faith buyer protection.-The buyer has to return the good to the original owner only if two things happen: the signal she receives indicates that the good was stolen and the court verifies title and enforces the law. In a separating equilibrium, the moral intermediary charges $\bar{p}^{h}$ for a legitimate good. The immoral intermediary charges $\bar{p}^{l}$. Counter intuitively, the signal $s$ plays no role in the price, because it is revealed after the intermediary has made her offer. Thus, the immoral intermediary does not know if the buyer will receive no signal and be willing to pay $\bar{p}^{h}$ or will receive a signal and be willing to pay only $\bar{p}^{l}$. Being forced to insure the buyer from being in bad faith, the intermediary will set a price $\bar{p}^{l}$. As before, a pooling equilibrium cannot be sustained and the change in social welfare vis-a-vis the baseline scenario is $\bar{W}_{G F}=\mu(\bar{V}-U)+(1-\mu)(1-s q)(\bar{V}-U)$. The latter falls with $s$ because an informative signal nullifies a welfare increasing transfer with probability $q$.

Full buyer protection.-Because the buyer can always legitimately retain a stolen good, she is always willing to pay up to her valuation. The only possible equilibrium is a pooling with unique price $\bar{p}^{h}$. The change of social welfare is maximal-i.e., $\bar{W}_{B}=\bar{V}-U$-and does not depend on either $\mu$ or $q$. The following lemma summarizes: 
Lemma 1: Given A1-A3, if $V=\bar{V}$, moral intermediaries buy the good at $U$ and immoral ones steal it. Under both owner and good-faith buyer protection, the only equilibrium is separating: i.e., legitimate goods are sold at $\bar{p}^{h} \equiv \bar{V}$ and stolen ones at $\bar{p}^{l} \equiv(1-q) \bar{V}$. Under full buyer protection, the only equilibrium is pooling and the unique price $\bar{p}^{h}$. The change of social welfare is highest (lowest) under full buyer (owner) protection.

\subsection{An Economy With Low Valuation Buyers}

If buyers have low valuation, moral intermediaries stay out of the market because the highest possible resell price is lower than the purchase price. The buyer anticipates that all goods on the market are stolen and hence discounts the probability of having to return the good while deciding whether to accept the intermediary's offer.

Owner protection. - In this case, the price equals the buyer's expected value $\underline{p}^{l} \equiv(1-q) \underline{V}$ and the change of social welfare will be given by $\underline{W}_{O}=-(1-\mu)(1-q)(U-\underline{V})$. If buyers have low valuation, transfers result in a social loss. Thus, as the market shrinks because $\mu$ rises or the legal system becomes more effective, social welfare increases.

Good-faith buyer protection.-Buyers have to return the good with probability $q$ only if the signal is informative. Thus, immoral intermediaries have a choice between selling always the good by charging $\underline{p}^{l}$ or selling the good only when the signal is not informative by charging $\underline{p}^{h} \equiv \underline{V}$. The former strategy maximizes welfare and thus $\underline{W}_{G F}=-(1-\mu)(1-s q)(U-\underline{V})$. Full buyer protection.-Because buyers never have to return the good, the price is $\underline{p}^{h}$ and the change of social welfare is $\underline{W}_{B}=-(1-\mu)(U-\underline{V})$. Summarizing:

Lemma 2: Given A1-A3, if $V=\underline{V}$ only immoral intermediaries stay in the market. They steal the good and sell it at $\underline{p}^{h} \equiv \underline{V}$ under full buyer protection and at $\underline{p}^{l} \equiv(1-q) \underline{V}$ otherwise. The change of welfare is highest (lowest) under owner (full buyer) protection.

\subsection{Endogenous Institutions Selection}

At time $t_{0}$ society chooses an institution on the basis of the expected change of welfare $W_{i}$, with $i \in\{O, G F, B\}$, and two mean zero shocks to society's preferences for the rules assuring higher buyer protection-i.e., $\varepsilon_{j}$ with for $j \in\{G F, B\}$-distributed according to the density $f$ on $[-\infty, \infty]$. Thus, when for instance $V=\underline{V}$, the probability that institution $\tilde{i} \neq j$, with $\tilde{i} \in\{O, G F\}$, is preferred to $j$ is $P\left(\underline{W}_{\tilde{i}}-\underline{W}_{j}+\varepsilon_{\tilde{i}} \geq 0\right)$. By taking the derivatives with 
respect to the exogenous parameters of the three possible pair-wise comparisons for each of the two possible economies we can assess how society's institutional choice is affected by both $\mu$ and $q$ (see also Guerriero, [2011]). As discussed in the appendix:

Proposition 1: Given A1-A3, the probability that society will move toward more protection of the buyer will: 1 . increase with the share of moral types $\mu$ and fall with the quality of the legal system $q$ whenever the original owners have the highest valuation; 2. decrease with $\mu$ and rise with $q$ whenever the potential buyers have the highest valuation.

In an economy with low valuation buyers, it is important to adopt a rule that facilitates the return of stolen goods to the original owner. Thus, in principle, owner protection will be favored. Yet, the greater the share of moral intermediaries, the more protection will be afforded to buyers. This is because moral intermediaries will exit the market avoiding undesirable transfers. In a sense, legal protection for original owners is unnecessary if strong moral norms prevent welfare-decreasing transactions. In contrast, the greater the probability of law enforcement, the more efficiently owner protection undoes undesirable transfers and, hence, the less desirable buyer protection is. These results are reversed in economies when $V=\underline{V} .{ }^{10}$ Next, we will assess how robust proposition 1 is to alternative assumptions.

\section{Robustness to Alternative Assumptions}

The original owner can protect her property.-The original owner can now impose a cost of stealing $C$ on the intermediary by spending $C$ - e.g., buying an alarm or a lock or placing his property in a safe. Clearly enough, the original owner will either set $C$ equal to a value deterring theft or to zero. Also, because the buyer's payoff is not directly affected by $C$ the equilibrium prices will be unaffected. In an economy with high valuation buyers, an original owner willing to deter theft should impose on the immoral intermediary a loss equal to the difference between the resale price of stolen goods and the net payoff from legal resale. In an economy with low valuation buyers, instead, legal resale is not an option and the minimum level of private protection deterring theft has to match the resale price. Thus, a stronger legal protection of the original owner at the same time reduces the expected loss from theft

\footnotetext{
${ }^{10}$ Two untested comparative statics concern $\Delta$ and $s$. The former (latter) increases (decreases) the probability that society will move toward more protection of the buyer (good faith buyer protection) by decreasing the potential for stealing (the probability that a stolen good is returned to the original owner).
} 
and, in turn, the incentives for private protection and decreases the price charged for stolen good and thus the cost of private protection. The combination of these effects produces a non-monotonic relationship between the protection afforded to the original owner by the law and the original owner's private effort. Indeed, if buyers have the highest valuation:

Lemma 3: Given A1-A3, if $V=\bar{V}$, there are two values of $\theta$-i.e., $\bar{\theta}_{G F}$ and $\bar{\theta}_{O}$ with $\bar{\theta}_{G F} \leq \bar{\theta}_{O} \leq \theta^{*}$ - such that the original owner: 1. never protects her property if $\theta<\bar{\theta}_{G F}$; 2 . protects her property only under good-faith buyer protection if $\bar{\theta}_{G F} \leq \theta<\bar{\theta}_{O}$; 3. protects her property under both owner and good-faith buyer protection if $\theta \geq \bar{\theta}_{O}$.

This non-monotonicity is evident when $\bar{\theta}_{G F} \leq \theta<\bar{\theta}_{O}$. Here, should the legal system start to protect somehow the original owner-i.e., a reform from full buyer to good-faith buyer protection, she will respond by protecting her property: that is, legal and private protection are complements. Yet, an even stronger legal protection-i.e. a reform toward owner protection - will completely discourage private protection making the two decisions substitutes. Our conclusions differ from the Schwartz and Scott's (2010) claim that the two protection types are always substitutes because endogenizing the market structure unveils key feedbacks of the law on prices. Also our approach stresses that even if irrelevant for institutional design, $\theta$ significantly shapes private protection by decreasing its cost because it makes for the immoral intermediary relatively more convenient buying than stealing. The whole analysis is similar when $V=\underline{V}$ with the caveat that the thresholds we identify could not be in the relevant parameter range when either $q$ or $\mu$ are sufficiently high:

Lemma 4: Given A1-A3, if $V=\underline{V}$, there are three values of the inverse measure of the potential for stealing-i.e., $\underline{\theta}_{G F}, \underline{\theta}_{B}$ and $\underline{\theta}_{O}$ with $\underline{\theta}_{G F} \leq \underline{\theta}_{B}=\underline{\theta}_{O}=\mu$-such that the original owner: 1. never protects her property if $\theta<\underline{\theta}_{G F}$; 2. protects her property only under good-faith buyer protection if $\underline{\theta}_{G F} \leq \theta<\underline{\theta}_{B}$; 3. always protects her property if $\theta \geq \underline{\theta}_{B}$. Thus proposition 1 remains unaffected in the most likely case in which $\theta$ is sufficiently small-i.e., either $\theta<\bar{\theta}_{G F}$ or $\theta<\underline{\theta}_{G F}$, and the following exceptions arise otherwise:

i) For $V=\bar{V}$ and $\bar{\theta}_{G F} \leq \theta<\bar{\theta}_{O}$, the probability that society will prefer good-faith buyer protection to owner protection will increases with the quality of the legal system $q$;

ii) For $V=\bar{V}$ and $\theta \geq \bar{\theta}_{O}$, the probability that society will move away from full buyer protection will increase with $q$ and will be insensitive to changes in $\mu$; 
iii) For $V=\underline{V}$ and $\underline{\theta}_{G F} \leq \theta<\underline{\theta}_{B}$, the probability that society will move toward more buyer protection increases with $\mu$;

iv) For $V=\underline{V}$ and $\theta \geq \underline{\theta}_{B}, \mu$ has no impact on the institutional design. ${ }^{11}$

The signal on the good's title is costly.-Let's now assume that the buyer receives the signal only if she invests $K>0$ in information gathering before dealing with the intermediaryi.e., this time the expert wants to be rewarded. This time, a buyer would be considered in bad faith if she has not invested in information given that the cost was reasonably low or if she has invested in information but the signal was uninformative. A glance to the equilibria discussed in lemma 1 and 2 reveals that buyers obtain a strictly positive expected payoff-i.e., $(1-\mu)(1-s) q \bar{V}((1-s) q \underline{V})$ for $V=\bar{V}(V=\underline{V})$-only under good faith buyer protection. Hence, provided that the cost of acquiring information is lower than the first (second) payoff for $V=\bar{V}(V=\underline{V})$, the buyer will buy the signal only under goodfaith buyer protection. Indeed, the cost of information destroys the separating equilibrium because the good intermediary cannot commit to offer a separating price lower than $\bar{V}-K$ in order to push the buyer to buy the signal. As a result, the immoral intermediary would be not discouraged to mimic the moral one and the equilibrium pooling price would be either be high enough to allow both intermediaries to stay in the market and the buyer to have a weakly positive expected payoff-i.e., $\bar{p}^{h, S} \equiv \mu \bar{V}+(1-\mu)(1-q) \bar{V}$-or equal to $\bar{p}^{l}$ if the moral intermediary exits the market because she finds unprofitable to buy. While the latter happens if $\bar{p}^{h, S}<U$ or $\theta>\theta^{S} \equiv \frac{q(1-\mu)}{1-q(1-\mu)}$, the former is the case if $\theta \geq \theta^{S} .{ }^{12}$

Similarly to the case of private protection of the her property rights by the owner, the extent of protection of her contract certainty by the buyer is a non-monotonic function of the corresponding protection afforded by the legal system. Also, for $V=\bar{V}$ and $\theta>\theta^{S}$ and for $V=\underline{V}$ the change in social welfare remains the same as in the benchmark case of section 3.1 under full owner protection and under full buyer protection, while it decreases by $K$ under good-faith buyer protection: this leaves unchanged proposition 1 . For $V=\bar{V}$

\footnotetext{
${ }^{11}$ The first two results can be interpreted as follows. For $\bar{\theta}_{G F}<\theta \leq \bar{\theta}_{O}$, good-faith buyer protection is desirable since private protection wipes out the supply of theft: this is especially welcome when stolen goods are often returned under other rules - i.e., $q$ is high. For $\theta \geq \bar{\theta}_{O}$, this effect extends also to owner protection. Since now the goods are never returned, $\mu$ has no role. The last two results, instead, are due to the fact that in those cases private protection nullifies transfers and only when it is absent $\mu$ has a role -i.e., it reduces theft.

${ }^{12}$ Notice that the $\theta>\theta^{S}$ scenario can be possible only when $\theta^{S}<\theta^{*}$ or $\mu>q^{-1}(2 q-1)$.
} 
and $\theta \geq \theta^{S}$, instead, all goods for sale are stolen and the change of social welfare becomes $(1-\mu)(1-q)(\bar{V}-U)$, which means that the probability of a reform toward more protection of the buyer will now rise with $\mu$. Yet, once again, this happens in the range of value of the inverse measure of the potential for stealing which we consider to be less realistic.

Moral buyers. - Let's now maintain that a share $\mu$ of buyers are moral and suffer a loss $m$ if they buy a good they know for sure it is stolen because of the purchasing price or because they received an informative signal. The remaining buyers are insensitive to guilt. Because an intermediary has either a proper or a defective title good, the price cannot be used to screen different types of buyers. Yet, two novel patterns arise: 1. for $\theta$ sufficiently high the prospect of not selling because of the match with a moral buyer induces immoral intermediary to buy the good; 2 . the model endogenously produces a loss due to the just discussed match between an immoral intermediary and a moral buyer. The loss is driven by the fact that every intermediary value the good at zero. Since, under a slightly stricter version of assumption A2, this social cost affect symmetrically all rules whether $V$ equals $\underline{V}$ or $\bar{V}$, Proposition 1 continues to hold true in the most likely case of a $\theta$ not too wide.

Relaxing assumptions A1, A2, and A3.-Relaxing our three key hypotheses increases the number of equilibria but leaves the testable prediction discussed in proposition 1 generally unchanged. The key features of the new equilibria are that: 1. if the $m$ is sufficiently small, both types of intermediaries would steal and moral costs would accrue to the changes of social welfare; 2. if assumption A2 is relaxed, a separating equilibrium can no longer be supported and there can be an equilibrium where moral intermediary buy, immoral ones steal and the pooling price is fixed so that all the uninformed buyers will buy; 3. if assumption A3 fails also the immoral intermediaries will find optimal to buy.

\section{Evidence}

In order to test our prediction we need, on one side, a sample of countries heterogeneous in the power - in terms of protection of the buyer over the original owner-rules and, on the other, proxies for both the share of moral types and the efficiency of public enforcement.

The dependent variable.-As already discussed in section 2, the legislation concerning good faith acquisition covers virtually all the range of transferable goods - i.e. movable and im- 
movable goods, works of art and financial instruments either embezzled or stolen. ${ }^{13}$ In order to avoid that any agency or immovable property protection related concerns could obscure our exercise, we have focused on the rules regulating the definition, requirements for the acquisition of the property right and length of acquisitive prescription of movable goods and movable works of art. ${ }^{14}$ To describe the exact legislation prevailing in the last 30 years around the world, we have approached members of the Lex Mundi-i.e., the largest international association of law firms (see also Djankov et al., [2003a]), contributors to the World Bank doing business project (World Bank, 2010) and academics affiliated to the law schools of the capital of each country for which we were able to observe either the share of moral types or the efficiency of public enforcement. At the end of this search process, we have been able to secure the contributions of at least one expert in 148 countries around the world and, in particular of all the 90 countries for which we observe both the share of moral types in society and the efficiency of public enforcement. The detailed sample is listed in Table 1.

Proxying the share of moral types and the efficiency of public enforcement.-Testing the model's prediction also requires building measures of the share of moral types in society and the efficiency of public enforcement. With regard to the former, we use answers from the five available waves of the World Value Surveys carried out in 1981-1982, 1989-1990, 1994-1995, 1999-2000 and 2005-2006 (Inglehart et al. 2010) and from the European Value Survey carried out in 1981, 1990, 1999 and 2008. Following Tabellini (2010), we consider four cultural dimensions: the level of generalized trust, ${ }^{15}$ a measure of the perceived ability of the population to control their own life, ${ }^{16}$ a proxy for the strength of the respect for other, ${ }^{17}$ and a metric of the importance of obedience toward parents. ${ }^{18}$ While trust and respect "ought

\footnotetext{
${ }^{13}$ Embezzlement is the act of dishonestly appropriating or secreting assets by one or more individuals to whom such assets have been entrusted (Singer and La Fond, 2010).

${ }^{14}$ The terms of acquisitive prescription relates to the possibility for the original owner to reclaim a lost or stolen good in court.

${ }^{15}$ This is the share of respondents answering "Most people can be trusted" to the question: "Generally speaking, would you say that most people can be trusted or that you cant be too careful in dealing with people?"

${ }^{16}$ This is the unconditional average response to the question: "Some people feel they have completely free choice and control over their lives, while other people feel that what we do has no real effect on what happens to them. Please use this scale (from 1 to 10) where 1 means "none at all" and 10 means "a great deal" to indicate how much freedom of choice and control in life you have over the way your life turns out".

${ }^{17}$ This is the share of respondents mentioning "tolerance and respect for other people" as an important quality that children should be encouraged to learn.

${ }^{18}$ This is the share of respondents mentioning "obedience" as an important quality that children should be encouraged to learn.
} 
to encourage welfare-enhancing social interactions, such as anonymous exchange or participation in the provision of public goods, [control is supposed to foster] an entrepreneurial environment where individuals seek to take advantage of economic opportunities" (Tabellini, 2010) and obedience to curb such spirit. On top of this discussion, we are going to rely on the variables trust, control, respect and obedience considered one at the time to avoid multicollinearity issues. Also, in order to capture the underlying variation of these indicators, we will alternatively include their first principal component-i.e. culture - as extracted from the whole data set with all individual responses (see also Tabellini [2010]).

Turning to the efficiency of public enforcement, we follow Djankov et al. (2003a) and consider the law sub-component of the index developed by the International Country Risk Guide (Gwartney, Lawson, and Block, 2008). Such index is not survey based but built upon a relative ranking of the quality of the public enforcement of the law across countries; law ranges from 1 to 10 with higher values capturing a stronger and more impartial legal system. Methodology.- Several countries have reformed over the sample some details of their legislation. In order to fully exploit the variation over country, time and power-in terms of protection of the buyer over the original owner - of the prevailing rules we will estimate two models: 1. a GMM model with dependent variable the length of acquisitive prescription; 2 . a GMM model with dependent a summary index aggregating the variation across definitions and requirements for the acquisition of the property right. ${ }^{19}$ These models will be repeated for every major category of legal case: lost, stolen or embezzled movable goods. ${ }^{20}$

\section{Concluding Comments}

The relevance of the rules balancing the use of coercion - i.e. theft or embezzlement - and pricing mechanisms in transferring the property of a good are key for economic development

\footnotetext{
${ }^{19}$ In order to select the only relevant features and their relative relevance in shaping the underlying "probuyer" construct, we will follow Rosenthal and Voeten (2007) and use a two-parameter multinomial logit item response model to aggregate the single indexes.

${ }^{20} \mathrm{~A}$ very preliminary and incomplete evidence can be extracted from the countries which were part of the communist block. Consistent with the testable prediction, the improvement in the quality of the public enforcement and the substantial stickiness in moral attitudes after this substantially exogenous shock (Alesina and Fuchs-Schündeln, 2007) have produced a significantly longer prescription of the proprietary remedy of the owner. Indeed, the mean prescription increased from the value of 3 imposed by the soviet Civil Code enacted in 1964 and prevailing before 1989 to the value of 15.34 years calculated for the period 1989-2011.
} 
especially in the aftermath of an agency-failure driven financial crisis. Yet, the determinants of these settings are still poorly understood: here, we developed an information theory of "endogenous legal institutions" (see also Aghion et al, [2010]; Guerriero, [2011]), focusing on the choice of the power in terms of protection of the buyer over the original owner of rules regulating good faith purchases. 


\section{Appendix}

\section{Proof of Lemma 1}

Given A1-A3, a glance to table 1 is enough to notice that, under owner protection, the payoff of the moral intermediary is highest when she buys the good and resells it at $\bar{p}^{h}=\bar{V}$ and that the immoral intermediary is better off stealing and selling the good at $\bar{p}^{l}=(1-q) \bar{V}$. These strategies produce a separating equilibrium. In a pooling equilibrium the moral intermediary would purchase the good from the original owner while the bad one would steal it. Yet, because both types should charge the same price and the moral intermediary would charge $\bar{V}$, the immoral intermediary would earn a payoff equal to $(1-s) \bar{V}$ because a share $s$ of the buyers will see an informative signal. Therefore, the immoral type would be better

off charging $(1-q) \bar{V}$ and selling for sure: this makes the separating equilibrium also the unique equilibrium under owner protection. A similar line of reasoning clarifies why there is a unique separating equilibrium under good-faith buyer protection.

Under full buyer protection, instead, the buyer will buy at any price lower than or equal to $\bar{V}$ and, in particular, $\bar{V}$. The immoral intermediary will steal the good, while the moral one buy it because of assumption A2. In this case the unique equilibrium is pooling.

\section{Proof of Proposition 1}

The probability that society leans towards more buyer protection is characterized by:

$P(B \succ O)=P\left((1-\mu) q \Delta+\varepsilon_{B} \geq 0\right) ; P(B \succ G F)=P\left((1-\mu) s q \Delta+\varepsilon_{B}-\varepsilon_{G F} \geq 0\right) ;$

$P(G F \succ O)=P\left((1-\mu)(1-s) q \triangle+\varepsilon_{G F} \geq 0\right)$

if $V=\bar{V}$ and by

$P(B \succ O)=P\left(\varepsilon_{B}-(1-\mu) q \Delta \geq 0\right) ; P(B \succ G F)=P\left(\varepsilon_{B}-\varepsilon_{G F}-(1-\mu) s q \Delta \geq 0\right) ;$

$P(G F \succ O)=P\left(\varepsilon_{G F}-(1-\mu)(1-s) q \triangle \geq 0\right)$;

if $V=\underline{V}$. The comparative statics in proposition 1 can be easily checked by inspection.

\section{References}

Acemoglu, Daron, and Alexander Wolitzky. 2011. "The Economics of Labor Coercion." Forthcoming Econometrica.

Acemoglu, Daron, and Simon Johnson. 2005. "Unbundling Institutions." Journal of 
Political Economy, 113: 949-995.

Aghion, Philippe, Yann Algan, Pierre Cahuc, and Andrei Shleifer. 2010. "Regulation and Distrust." Quarterly Journal of Economics, 125: 1015-1049.

Alesina, Alberto, and Fuchs-Schündeln. 2007. "Goodbye Lenin (or Not?): The Effect of Communism on People." American Economic Review, 97: 1507-1528.

B́nabou, Roland, and Jean Tirole. 2006. "Incentives and Prosocial Behaviors." American Economic Review, 96: 16521678.

Ben-Shahar, Omri and Alon Harel. 1995. "Blaming the Victim: Optimal Incentives for Private Precautions against Crime." Journal of Law, Economics and Organization, 11: 434-455.

Cooper, Joel. 2007. Cognitive Dissonance: 50 Years of a Classic Theory. London: Sage publications.

Dari-Mattiacci, Giuseppe, Carmine Guerriero, Arthur F. Salomons. 2011. "The Law and Economics of Good-Faith Purchase." Unpublished.

Djankov, Simeon, Rafael La Porta, Florencio Lopez-de-Silanes, and Andrei Shleifer. 2003a. "Courts." Quarterly Journal of Economics, 118: 453-517.

Djankov, Simeon, Edward Glaeser, Rafael La Porta, Florencio Lopez-de-Silanes, and Andrei Shleifer. 2003b. "The New Comparative Economics." Journal of Comparative Economics, 31: 595-619.

Glaeser, Edward L., and Andrei Shleifer. 2003. "The Rise of the Regulatory State." Journal of Economic Literature, 41: 401-425.

Guerriero, Carmine. 2011. "The Political Economy of (De)Regulation: Theory and Evidence from the U.S. Electricity Market." Unpublished.

Guiso, Luigi, Paola Sapienza and Luigi Zingales. 2009. "Cultural Biases in Economic Exchange." Quarterly Journal of Economics, 124: 1095-1131. 
Gwartney, James D., Joshua C. Hall, and Robert Lawson. 2010. "Economic Freedom of the World: 1970-2010." Vancouver, Canada: The Fraser Institute.

Inglehart, Ronald. 2010. "World Values Surveys and European Values Surveys, 19811984, 19901993, 19951997 and and 2005-2006." Ann Arbor, MI: Institute for Social Research.

Levmore, Saul. 1987. "Variety and Uniformity in the Treatment of the Good-Faith Purchaser." Journal of Legal Studies, 16: 43-65.

Medina, Barak. 2003. "Augmenting the Value of Ownership by Protecting It Only Partially: The 'Market Overt' Rule Revisited." Journal of Law, Economics and Organization, 19: 343-372.

Piccione, Michele, and Ariel Rubinstein. 2007. "Equilibrium in the Jungle." Economic Journal, 117: 883-896.

Rose, Caspar. 2010. "The Transfer of Property Rights by Theft: An Economic Analysis." European Journal of Law and Economics, 30: 247-266

Rosenthal, Howard, and Erik Voeten. 2007. "Measuring Legal Systems." Journal of Comparative Economics, 35: 711-728.

Salomons, Arthur F. 2009. "On the Economics of Good Faith Acquisition Protection in the DCFR." In Alessandro Somma (ed.), The Politics of the Draft Common Frame of Reference. Alphen aan den Rijn: Kluwer Law International.

Schwartz, Alan and Robert E. Scott. 2011. "Rethinking the Laws of Good Faith Purchase." Forthcoming Columbia Law Review.

Singer, Richard G., and John Q. La Fond. 2010. "Criminal Law." 5th Edition. Aspen, CO: Aspen Publishers, Inc.

Tabellini, Guido. 2010. "Culture and Institutions: Economic Development in the Regions of Europe." Journal of European Economic Association, 8: 677-716.

World Bank. 2010. "Doing Business Final Report." Unpublished and available at http://www.doingbusiness.org/Documents/FullReport/2010 


\section{Tables}

Table 1: Intermediary's Payoffs Under Owner and Good Faith Buyer Protection If $V=\bar{V}$

\begin{tabular}{|c|c|c||c|c|}
\hline & \multicolumn{2}{|c||}{ Moral Intermediary } & \multicolumn{2}{c|}{ Immoral Intermediary } \\
\hline & $\bar{p}^{h}$ & $\bar{p}^{l}$ & $\bar{p}^{h}$ & $\bar{p}^{l}$ \\
\hline Buy & $\bar{V}-U$ & $(1-q) V-U$ & $\bar{V}-U$ & $(1-q) V-U$ \\
\hline Steal & $(1-s) \bar{V}-m$ & $(1-q) \bar{V}-m$ & $(1-s) \bar{V}$ & $(1-q) \bar{V}$ \\
\hline
\end{tabular}

\section{Table 2: Sample}

\footnotetext{
Albania*; Algeria*; Andorra; Angola; Argentina*; Armenia*; Australia*; Austria*; Azerbaijan*; Bahamas; Bahrain; Bangladesh*; Barbados; Belarus; Belgium*; Belize; Benin; Bolivia; Bosnia and Herzegovina*; Botswana; Brazil*; Bulgaria*; Burkina Faso*; Burundi; Cameroon; Canada*; Central African Republic; Chad; Chile*; China*; Colombia*; Republic Of Congo; Costa Rica; Cote d'Ivoire; Croatia*; Cyprus*; Czech Republic*; Denmark*; Dominican Republic*; Ecuador; Egypt*; El Salvador*; Estonia*; Ethiopia*; Fiji; Finland*; France*; Gabon; Georgia*; Germany*; Ghana*; Greece*; Guatemala*; Guinea-Bissau; Guyana; Haiti; Honduras; Hong Kong*; Hungary*; Iceland*; India*; Indonesia*; Iran*; Iraq; Ireland*; Israel*; Italy*; Jamaica; Japan*; Jordan*; Kazakhstan; Kenya; Kosovo; Kuwait; Kyrgyz Republic*; Latvia*; Lesotho; Lithuania*; Luxembourg*; Macedonia*; Madagascar; Malawi; Malaysia*; Mali*; Malta; Mauritania; Mauritius; Mexico*; Moldova*; Mongolia; Montenegro*; Morocco*; Mozambique; Myanmar; Namibia; Nepal; Netherlands*; New Zealand*; Nicaragua; Niger; Nigeria*; Norway*; Oman; Pakistan*; Panama; Papua New Guinea; Paraguay; Per*; Philippines*; Poland*; Portugal*; Puerto Rico; Romania*; Russia*; Rwanda*; Saudi Arabia; Scotland; Senegal; Serbia*; Sierra Leone; Singapore*; Slovak Republic*; Slovenia*; South Africa*; South Korea*; Spain*; Sri Lanka; Sweden*; Switzerland*; Syria; Taiwan*; Tanzania*; Thailand*; Togo; Trinidad and Tobago*; Tunisia; Turkey*; Uganda*; Ukraine*; United Arab Emirates; United Kingdom*; United States*; Uruguay*; Venezuela*; Vietnam*; Democratic Republic of Congo; Zambia*; Zimbabwe*.
}

Note: 1. Data on culture and the efficiency of public enforcement are available only for the 90 countries followed by an asterisk. 